\title{
Comparison of the haemostatic properties of conventional monopolar and bipolar transurethral resection of the prostate in patients on oral anticoagulants
}

Dirk P.J. Michielsen ${ }^{1}$, Danny Coomans ${ }^{2}$, Caroline Van Lersberghe ${ }^{3}$, Johan G. Braeckman ${ }^{1}$

1Department of Urology, Vrije Universiteit Brussel (VUB), Belgium

2Department of Biostatistics and Medical Informatics, Faculty of Medicine

and Pharmacy, Vrije Universiteit Brussel (VUB), Belgium

${ }^{3}$ Department of Anaesthesiology, UZ Brussel, Vrije Universiteit Brussel (VUB), Belgium

Submitted: 22 July 2010

Accepted: 18 September 2010

Arch Med Sci 2011; 7, 5: 858-863

DOI: 10.5114/aoms.2011.25562

Copyright @ 2011 Termedia \& Banach

\author{
Corresponding author: \\ Dirk Michielsen MD, PhD \\ UZ Brussel \\ Department of Urology \\ Laarbeeklaan 101 \\ 1090 Brussels \\ Belgium \\ Phone: +3224777900 \\ Fax: +3224776818 \\ E-mail: \\ dirk.michielsen@uzbrussel.be
}

\begin{abstract}
Introduction: The aim of study is comparing the haemostatic properties of conventional monopolar resection (TURP) and bipolar transurethral resection in saline (TURIS) of the prostate in patients under chronic oral anticoagulants. Material and methods: Out of a cohort group of 550 endoscopic resections for bladder outlet obstruction, 176 patients on chronic oral anticoagulant therapy required endoscopic resection either by monopolar TURP or bipolar TURIS technology. Changes in haemoglobin, blood transfusion, and clot retention were compared between both groups.

Results: Mean postoperative change in haemoglobin level was $-1.21 \pm 0.92 \mathrm{mg} / \mathrm{dl}$ in the TURP group compared to $-1.29 \pm 0.99 \mathrm{mg} / \mathrm{dl}$ in the TURIS group $(p=0.603)$. The need for blood transfusions and the mean numbers of units transfused did not significantly differ between the 2 groups. Clot retention appeared in 12 patients (15\%) in the TURP group compared to 13 patients $(13 \%)$ in the TURIS group $(p=0.828)$.

Conclusions: Despite promising experimental results of better haemostasis and deeper coagulation depth, bipolar technology does not permit one to reduce the amount of blood loss when compared to patients treated by conventional monopolar technology in this study group of patients on oral anticoagulation therapy. Patients on oral anticoagulants suffer more incidents of clot retention, which sometimes results in re-hospitalisation.
\end{abstract}

Key words: prostate, bipolar, transurethral resection of prostate.

\section{Introduction}

Conventional monopolar transurethral resection of the prostate is still the gold standard in the surgical treatment of benign prostatic hyperplasia [1]. Bipolar transurethral resection is advocated to claim this position [2]. This new technology permits one to obtain identical postoperative success rates and a lower peri- and postoperative complication rate. Autorino et al. highlighted the outcome regarding International Prostate Symptom Score (IPSS), QOL, flow rate and post-voiding residual after 4 years [3]. Furthermore, with the use of saline $0.9 \%$ instead of glycine the dreaded TUR syndrome can be avoided. A meta-analysis of all randomized controlled studies by Mamoulakis et al. showed that there was not a single TUR syndrome in the bipolar group [4]. 
Recent experimental laboratory investigations showed a lower bleeding rate and deeper coagulation capacity with the bipolar armamentarium $[5,6]$. This could lead to lower blood loss, fewer transfusions and a reduced risk of clot retention in the clinical setting. Randomised controlled clinical trials were completed to compare these parameters both with conventional monopolar and bipolar technology [4]. Of particular interest for this are patients under anticoagulation therapy, either antivitamins K or antiplatelets. Most of the time these therapeutic medications need to be continued, although they are not the surgeon's best friend. Therefore, we analysed this in patients under oral anticoagulants to see whether bipolar technology has an additional value for them.

\section{Material and methods}

Between April 2005 and February 2009, 176 patients on chronic oral anticoagulant therapy who required endoscopic transurethral resection of the prostate for bladder outlet obstruction were treated either by conventional monopolar or bipolar surgery. The minimal inclusion criteria for entry were an International Prostate Symptom Score of 13 or more, QOL index of 3 or more, and maximal urinary flow rates below $15 \mathrm{ml}$ per second. Exclusion criteria were neurogenic bladder, prostate cancer, previous prostatic or urethral surgery, and bladder stones.

A standard protocol was used regarding the replacement of oral coagulants with preoperative injections of low molecular weight heparins (LMWH) and the restart of oral anticoagulants in the early postoperative phase. Patients on antivitamin $\mathrm{K}$ stopped the intake of oral medication 5 days before surgery. The LMWH were started at a therapeutic dose. One day postoperatively, antivitamins were restarted. Patients on antiplatelets stopped the intake 7 days before surgery, had subcutaneous LMWH injections at therapeutic doses for 1 week and restarted their antiplatelets the day after resection. Patients with coronary stents on clopidogrel continued this medication.

The indications for chronic oral anticoagulant therapy are presented in Table I. Antivitamins were taken for atrial fibrillation, prosthetic heart valve and a history of deep venous thrombosis or pulmonary embolism. Aspirin was prescribed as a single treatment strategy after myocardial infarction or in combination with clopidogrel after coronary stenting.

All endoscopic resections were performed by two staff urologists (DM, JB). Both were familiar with the monopolar and bipolar equipment. A standard Olympus resectoscope (24 Fr) and an Olympus UES40 SurgMaster electrical current generator were used for both techniques. Monopolar TURP was done with standard loops using 175 W cutting power and $75 \mathrm{~W}$ coagulation power. Bipolar TURIS was performed using a bipolar electrode set at 270W for cutting and $75 \mathrm{~W}$ for coagulation. All procedures were performed with intermittent glycine $1.5 \%$ or saline $0.9 \%$ irrigation using general or spinal anaesthesia. A full blood count was determined $24 \mathrm{~h}$ after surgery.

Parameters of interest in the perioperative management were changes in haemoglobin, blood transfusion needed, duration of indwelling catheter placement and bladder irrigation, episodes of clot retention and duration of hospital stay.

All statistical tests performed were 2-sided and at the $5 \%$ level of significance (type I error). The 2 groups were compared using the independent $t$-test. Because of the large sample size the data were not required to have a normal distribution. Complications as TUR syndrome, clot retention, need for transfusion and urinary retention were assessed by Fisher's exact test. The $p$-values obtained were similar to the $\chi^{2}$ test with continuity correction. SPSS version 17.0 was used to perform the tests.

\section{Results}

Of 550 men with bladder outlet obstruction treated by transurethral endoscopic resection, 176 patients were under chronic anticoagulant therapy, i.e. antivitamins $\mathrm{K}$ in 92 patients, and antiplatelet therapy in 84 patients.

The conventional transurethral resection group included 78 patients (42 on antivitamins $\mathrm{K}$ and 36 on antiplatelets), while 98 patients were operated on using the bipolar TURIS technique (51 on antivitamins $\mathrm{K}$ and 47 on antiplatelets).

Mean postoperative drop in haemoglobin was $1.25 \pm 0.95 \mathrm{mg} / \mathrm{dl}$ in patients on chronic anticoagulant therapy compared to a decline of 1.26 $\pm 1.17 \mathrm{mg} / \mathrm{dl}$ in all the other patients of the cohort group $(p=0.950)$. No statistically significant

Table I. Aetiology for anticoagulants

\begin{tabular}{|lcc|}
\hline Variables & $\begin{array}{c}\text { Monopolar } \\
\text { TURP } \\
N(\%)\end{array}$ & $\begin{array}{c}\text { Bipolar } \\
\text { TURIS } \\
N(\%)\end{array}$ \\
\hline Antivitamins K & 42 & 50 \\
\hline \begin{tabular}{l} 
Atrial fibrillation \\
\hline Prosthetic heart valve
\end{tabular} & 21 & 21 \\
\hline Thromboembolic event & 19 & 1 \\
\hline Antiplatelets & 36 & 28 \\
\hline Coronary stenting & 21 & 48 \\
\hline Prevention & 15 & 27 \\
\hline
\end{tabular}

TURP - transurethral resection of prostate, TURIS - transurethral resection in saline of prostate, $\mathrm{N}$-number 
difference in haemoglobin drop was observed between patients whether they were on anticoagulants or not, both in the conventional monopolar resection group $(p=0.750)$ and in the bipolar TURIS group $(p=0.866)$.

Postoperative clot retention was observed in 25 patients on anticoagulant therapy $(14.2 \%)$ and in 22 non-anticoagulated patients $(5.9 \%)(p=0.006)$.

In patients on oral anticoagulants, the operation technology did not influence the outcome. Patientrelated and operation characteristics of both resection groups are reported in Table II. In the conventional monopolar resection group, $52 \mathrm{pa}-$ tients $(67 \%)$ were treated under spinal anaesthesia and $26(33 \%)$ under general anaesthesia. In the bipolar group, the distribution was $76(78 \%)$ and 22 (22\%) respectively. Although volume measurements of both the prostate and the adenoma were similar, resection time and resection speed were statistically significantly slower in the bipolar TURIS group $(p<0.000)$.

Mean postoperative change in haemoglobin level was $-1.21 \pm 0.92 \mathrm{mg} / \mathrm{dl}$ in the TURP group compared to $-1.29 \pm 0.99 \mathrm{mg} / \mathrm{dl}$ in the TURIS group $(p=0.603)$. Blood transfusions were required in 2 patients in the TURP group compared to 1 in the TURIS group $(p=0.585)$. No TUR syndromes were observed in either group.

Clot retention appeared in 12 patients (15\%) in the TURP group compared to 13 patients (13\%) in the TURIS group ( $p=0.828)$. In the TURP group, 6 clot incidents appeared immediately after catheter removal and were successfully resolved. Six patients with delayed bleeding needed to be re-hospitalized 1 or 2 weeks later. In the TURIS group, there were 8 early and five late incidents. All clot retention incidents were managed conservatively by reinsertion of an indwelling catheter, manual removal of the blood clots and continuation of bladder irrigation until gross haematuria resolved.
Sub-analysis of each mean of anticoagulation showed no significant difference between the two technologies. Patients on oral antivitamins $\mathrm{K}$ had a drop in haemoglobin of $0.92 \pm 0.83 \mathrm{mg} / \mathrm{dl}$ in the monopolar group and $1.16 \pm 1.11 \mathrm{mg} / \mathrm{dl}$ in the bipolar group $(p=0.266)$. For patients on antiplatelets this was $1.55 \pm 0.92 \mathrm{mg} / \mathrm{dl}$ and $1.41 \pm 0.83 \mathrm{mg} / \mathrm{dl}$, respectively ( $p=0.508)$.

\section{Discussion}

The prostate has a rich blood supply. The development of the adenoma is accompanied by a significant increase of angiogenesis and formation of aberrant blood vessels. This can cause substantial intra-operative bleeding. The size of the vessels in the prostatic adenoma is also of importance [7]. Huang et al. studied the diameters of the microvessels in 22 prostates [7]. The mean diameter in hyperplasic prostates was $21.19 \pm 12.8 \mu \mathrm{m}$, but $0.1 \%$ of the vessels measured $125-140 \mu \mathrm{m}$ [7]. The coagulation depth should extend far enough to seal these large blood vessels.

Recent laboratory work was done to investigate the haemostatic capacity of bipolar devices. WendtNordahl et al. examined the blood loss in a modified model of the isolated blood-perfused porcine kidney model [5]. They observed lower bleeding rates $(15.16 \pm 3.31 \mathrm{~g} / \mathrm{min})$ with the bipolar device than with the monopolar device $(20.78 \pm 1.52$ g/min) [5]. Experimental work by Huang et al. reported that the coagulation zones are statistically significantly deeper with a bipolar device (237.73 $\pm 20.12 \mu \mathrm{m})$ than with monopolar devices (200.75 $\pm 19.34 \mu \mathrm{m})$ in canine prostates [6]. It also appeared that the few larger blood vessels are sealed by bipolar technology. Furthermore, Wendt-Nordahl et al. showed that bipolar cutting ended in a marginally deeper coagulation zone (236.25 $\pm 36.69 \mu \mathrm{m}$ ) compared with the extent of the

Table II. Patient-related and operation characteristics of both groups

\begin{tabular}{|lcccc|}
\hline Variables & $\begin{array}{c}\text { Monopolar TURP } \\
\text { Mean }( \pm \text { SD) }\end{array}$ & $\begin{array}{c}\text { Bipolar TURIS } \\
\text { Mean }( \pm \text { SD) }\end{array}$ & Value of $p$ & $\begin{array}{c}\text { 95\% confidence } \\
\text { interval of the difference }\end{array}$ \\
\hline Age [year] & $73.64( \pm 8.76)$ & $75.11( \pm 7.83)$ & 0.242 & $(-3.943,1.001)$ \\
\hline Prostate $[\mathrm{ml}]$ & $55.61( \pm 24.01)$ & $55.11( \pm 16.29)$ & 0.902 & $(-7.575,8.584)$ \\
\hline Adenoma $[\mathrm{ml}]$ & $32.72( \pm 15.04)$ & $34.68( \pm 10.67)$ & 0.447 & $(-7.065,3.139)$ \\
\hline PSA $[\mathrm{ng} / \mathrm{ml}]$ & $5.35( \pm 5.41)$ & $9.05( \pm 16.72)$ & 0.148 & $(-8.745,1.340)$ \\
\hline Operative time $[\mathrm{min}]$ & $37( \pm 19)$ & $57( \pm 22)$ & 0.000 & $(-26.31,-13.69)$ \\
\hline Resection weight $[\mathrm{g}]$ & $20.21( \pm 11.88)$ & $19.44( \pm 11.53)$ & 0.670 & $(-2.789,4.329)$ \\
\hline Resection speed $[\mathrm{g} / \mathrm{min}]$ & $0.62( \pm 0.40)$ & $0.38( \pm 0.25)$ & 0.000 & $(0.139,0.341)$ \\
\hline Indwelling catheter [day] & $1.77( \pm 1.02)$ & $1.79( \pm 1.78)$ & 0.942 & $(-0.430,0.463)$ \\
\hline Hospital stay [day] & $4.91( \pm 3.56)$ & $4.35( \pm 3.14)$ & 0.330 & $(-0.564,1.671)$ \\
\hline
\end{tabular}

TURP - transurethral resection of prostate, TURIS - transurethral resection in saline of prostate, SD - standard deviation 
coagulation effect after monopolar cutting (216.00 $\pm 42.24 \mu \mathrm{m}$ ) [5].

The deeper coagulation capacity of bipolar devices may be attributed to the different mechanism of cutting and a higher baseline power setting. Conventional monopolar devices remove tissue by direct heating, whereas the majority of heat is dissipated into steam and little is conducted to coagulate tissue [8]. A power setting of $175 \mathrm{~W}$ is used for cutting and $75 \mathrm{~W}$ for coagulation. Tissue cutting in bipolar devices depends on the plasma effect. High frequency energy runs from the active pole through the conductive fluid $(\mathrm{NaCl} 0.9 \%)$ to the return pole. Energetic species of the charged ions cause breakage of organic carbon-carbon and carbon-nitrogen bonds $[9,10]$. Furthermore, the plasma effect can effectively coagulate oozing vessels at the surface of the resected tissue [11]. A higher power setting of respectively $270 \mathrm{~W}$ and $75 \mathrm{~W}$ is used.

The results of experimental research open up possibilities in the clinical setting. If intra-operative blood loss is reduced, the operation field becomes "clearer". This allows the coagulation mode to be used more accurately to seal all bleeding points. However, experimental advantages are not always clearly translated into clinical results. Table III lists the haemoglobin changes from patients in randomized controlled trials comparing conventional monopolar and bipolar technology [3, 9, 12-14]. Only $\mathrm{Ho}$ et al. reported a statistically significantly lower blood loss using Olympus TURIS [13]. In all other investigations, there were no statistically significant differences between both technologies.

Clot retention is another annoying complication resulting from peri- and postoperative bleeding. It may lead to longer catheterization times and sometimes even to a need for reinterventions. Table IV lists the number of clot retentions in all published randomized controlled trials [9, 12-19]. Only Ruthann et al. reported a statistically significant difference in favour of bipolar technology [19]. A meta-analysis by Mamoulakis et al. showed that one needs to treat 20 patients with bipolar instead of monopolar resection to avoid one incident of clot retention [4].

In the present study we examined the haemostatic capacity of both monopolar and bipolar technology in patients on oral anticoagulation therapy. Antivitamins K and antiplatelets are important medications for patients at risk for arterial or venous thromboembolism. Continuing intake of these medications increases the risk of excessive and prolonged bleeding in the perioperative period. Therefore, most surgeons prefer to discontinue oral anticoagulants. This is not without risk. Bell et al. reported a tendency for hypercoagulation after transurethral resection of the prostate [20]. Six $h$ after surgical intervention, there is a significant rise of the thrombin/thromboplastin complex and a decrease of thromboplastins. This complication

Table III. Changes in haemoglobin in randomized controlled trials

\begin{tabular}{|llccc|}
\hline Study & Comparing & $N / N$ & $\mathrm{Hb} / \mathrm{Hb}$ & Value of $p$ \\
\hline Singh et al. [10] & TURP vs. VISTA & $30 / 30$ & $-1.2 /-1.2$ & 0.91 \\
\hline lori et al. [13] & TURP vs. Gyrus & $26 / 27$ & $-1.8 /-1.2$ & 0.72 \\
\hline Autorino et al. [3] & TURP vs. Gyrus & $35 / 35$ & $-1.0 /-0.8$ & 0.09 \\
\hline Ho et al. [14] & TURP vs. TURIS & $52 / 48$ & $-1.8 /-1.2$ & 0.00 \\
\hline Michielsen et al. [15] & TURP vs. TURIS & $120 / 118$ & $-1.3 /-1.4$ & 0.29 \\
\hline
\end{tabular}

$\mathrm{Hb}$ - haemoglobin

Table IV. Clot retention in randomized controlled trials

\begin{tabular}{|llccc|}
\hline Study & Comparing & $N / N$ & Clot retention/Clot retention & Value of $p$ \\
\hline Singh et al. [10] & TURP vs. VISTA & $30 / 30$ & $0 / 0$ & 1.000 \\
\hline Yang et al. [16] & TURP vs. Gyrus & $59 / 58$ & $7 / 9$ & 0.601 \\
\hline Seckiner et al. [17] & TURP vs. Gyrus & $24 / 24$ & $0 / 2$ & 0.489 \\
\hline Patankar et al. [18] & TURP vs. Gyrus & $51 / 52$ & $2 / 0$ & 0.243 \\
\hline De Sio et al. [19] & TURP vs. Gyrus & $35 / 35$ & $4 / 2$ & 0.673 \\
\hline Erturhan et al. [20] & TURP vs. Gyrus & $120 / 120$ & $17 / 2$ & 0.000 \\
\hline lori et al. [13] & TURP vs. Gyrus & $26 / 27$ & $5 / 1$ & 0.100 \\
\hline Ho et al. [14] & TURP vs. TURIS & $52 / 48$ & $2 / 3$ & 0.669 \\
\hline Michielsen et al. [15] & TURP vs. TURIS & $120 / 118$ & $6 / 4$ & 0.749 \\
\hline
\end{tabular}


is responsible for the high incidences of venous thrombosis (6.8-10\%) and pulmonary embolism after TURP (0.2-2.2\%) [21, 22].

The guidelines on anticoagulants and TURP that we have used for years are certainly disputable. We routinely observe an appropriate wash-out period. Patients on antivitamin $\mathrm{K}$ stop the intake five days before endoscopic surgery. Replacement therapy by low molecular weight heparins in a therapeutic dose is administered until the day of the operation. After surgery, intake of antivitamin $\mathrm{K}$ is restarted as soon as possible. Patients on antiplatelets interrupt this treatment one week before the surgery. Although it is not sustained by data in the literature, we substitute the antiplatelets with subcutaneously administered LMWH. We restart the oral prevention as soon as possible.

There is no uniform management strategy concerning anticoagulants and transurethral prostate resections. Do we really have to stop oral anticoagulation therapy? Parr et al. reported the outcome of 14 patients who had continued their oral anticoagulants throughout transurethral resection of the prostate or bladder [23]. Blood transfusion was needed in 4 patients (28\%). A drop of more than $2 \mathrm{~g} / \mathrm{dl}$ was observed in 3 patients (21\%). Furthermore, replacement therapy by heparins did not lead to more blood loss. Tscholl et al. examined 23 patients with or without continuous administration of intravenous heparin throughout the perioperative period [24]. In both groups, the mean blood loss was similar. The use of LMWH is supposed to be safer because platelet aggregation and vascular permeability decrease to a lesser extent than with intravenously injected heparin [25]. However, decreased bleeding rates after prevention with LMWH are not consistently reported in clinical trials [26].

The possible benefit of perioperative anticoagulation must be balanced against the increased risk of postoperative bleeding. It makes the risk of major bleeding in the first 48 postoperative $h$ increase by $0-4 \%$ for major and invasive procedures [27]. The risk of permanent disability or death after major bleeding is $1 \%$ to $6 \%$ [27]. Permanent disability or death after arterial thromboembolism is common (70-75\%) [27]. Venous thromboembolism is less risky but can cause permanent disability and death in $4 \%$ to $10 \%$ of cases [27]. In this analysis, early restart of anticoagulation therapy led to clot retention in $14.2 \%$ of the patients. Eleven patients were re-hospitalized.

In this matter, the choice of the endoscopic instrument and technique is an important factor. Each technology is conceived to reach two important goals: to limit perioperative blood loss and to allow the restart of oral anticoagulants as soon as possible, preferably the day after surgery.
In a clear operation field the coagulation mode can be used accurately to seal all bleeding points. A point of comparison of paramount importance between the conventional and the newer minimally invasive techniques for TURP should be their safety profile for bleeding incidents. Hoffman et al. compared 1898 patients treated by TURP or laser therapy in a large-scale meta-analysis [28]. Analysis of symptom improvement and urine flow slightly favoured conventional TURP. Laser therapy was superior regarding blood loss, clot retention and hospitalisation time. Ruszat et al. reported the excellent haemostatic properties of photoselective vaporization of the prostate in patients on ongoing oral anticoagulants [29].

We did not observe a substantial advantage with the use of bipolar technology with regard to the occurrence of bleeding complications. We did not note statistically significant differences in haemoglobin changes, the number of incidents with clot retention or the need for blood transfusions between the monopolar and bipolar TUR systems.

This study has some shortcomings. Whether the short-term change in haemoglobin is a valid parameter of blood loss is debatable. Therefore we aimed for a standardised scheme of intravenous fluid therapy. The assistance of a HemoCue photometer would be more appropriate, but also in all reported trials (Table III) this was not the case [30]. The decision to perform a blood transfusion is sometimes subjective. It is not only based on a measured haemoglobin level below $8 \mathrm{mg} / \mathrm{dl}$, but also on the cardiovascular status of the patient.

In conclusion, bipolar transurethral resection of the prostate claims the "gold standard" position of conventional monopolar technology for the surgical treatment of benign prostatic hyperplasia. This new technology has a proven low peri- and postoperative complication rate and a good clinical outcome. Experimental studies suggest that bipolar resection provides better haemostasis and deeper coagulation depth. However, these advantages in experimental research are not always translated into clinical practice. A review of randomized controlled trials failed to demonstrate a reduction of the preoperative and postoperative blood loss in patients treated by bipolar technology. Even in a study group of patients on oral anticoagulation therapy, bipolar technology does not seem to be superior. Whatever the technology used, patients on oral anticoagulants suffer more incidents of clot retention, which sometimes results in rehospitalisation.

\section{Acknowledgments}

Dirk P.J. Michielsen had full access to all the data in the study and takes responsibility for the integrity of the data and the accuracy of the data analysis. 
Study concept and design: Michielsen, analysis and interpretation of data: Michielsen, Coomans, drafting of the manuscript: Michielsen, Coomans, Van Lersberghe, Braeckman, critical revision of the manuscript for important intellectual content: Michielsen, Coomans, Van Lersberghe, Braeckman, statistical analysis: Michielsen, Coomans.

\section{References}

1. Reich O, Gratzke C, Stief CG. Techniques and long-term results of surgical procedures for BPH. Eur Urol 2006; 49: 970-8.

2. Mamoulakis C, Trompetter M, de la Rosette J. Bipolar transurethral resection of the prostate: the 'golden standard' reclaims its leading position. Curr Opin Urol 2009; 19: 26-32.

3. Autorino R, Damiano R, Di Lorenzo G, et al. Four-year outcome of a prospective randomised trial comparing bipolar plasmakinetic and monopolar transurethral resection of the prostate. Eur Urol 2009; 55: 922-9.

4. Mamoulakis C, Ubbink DT, de la Rosette JJ. Bipolar versus monopolar transurethral resection of the prostate: a systematic review and meta-analysis of randomized controlled trials. Eur Urol 2009; 56: 798-809.

5. Wendt-Nordahl G, Häcker A, Fastenmeier K, et al. New bipolar resection device for transurethral resection of the prostate: first ex-vivo and in-vivo evaluation. J Endourol 2005; 19: 1203-9.

6. Huang X, Wang XH, Qu LJ, Pu XJ, Zeng X. Bipolar versus monopolar transurethral resection of prostate: pathologic study in canines. Urology 2007; 70: 180-4.

7. Huang X, Wang XH, Wang HP, Qu LJ. Comparison of the microvessel diameter of hyperplastic prostate and the coagulation depth achieved with mono- and bipolar transurethral resection of the prostate. A pilot study on hemostatic capability. Scand J Urol Nephrol 2008; 42: 265-8.

8. Cabelin MA, Te AE, Kaplan SA. Transurethral vaporization of the prostate: current techniques. Curr Urol Rep 2000; 1: 116-23.

9. Singh H, Desai MR, Shrivastav P, Vani K. Bipolar versus monopolar transurethral resection of prostate: randomized controlled study. J Endourol 2005; 19: 333-8.

10. Wendt-Nordahl G, Häcker A, Reich O, Djavan B, Alken P, Michel MS. The Vista system: a new bipolar resection device for endourological procedures: comparison with conventional resectoscope. Eur Urol 2004; 46: 586-90.

11. Smith D, Khoubehi B, Patel A. Bipolar electrosurgery for benign prostatic hyperplasia: transurethral electrovaporization and resection of the prostate. Curr Opin Urol 2005; 15: 95-100.

12. Iori F, Franco G, Leonardo C, et al. Bipolar transurethral resection of prostate: clinical and urodynamic evaluation. Urology 2008; 71: 252-5.

13. Ho HS, Yip SK, Lim KB, Fook S, Foo KT, Cheng CW. A prospective randomized study comparing monopolar and bipolar transurethral resection of prostate using transurethral resection in saline (TURIS) system. Eur Urol 2007; 52: 517-22.

14. Michielsen DP, Debacker T, De Boe V, et al. Bipolar transurethral resection in saline - an alternative surgical treatment for bladder outlet obstruction? J Urol 2007; 178: 2035-9.

15. Yang S, Lin WC, Chang HK, et al. Gyrus plasmasect: is it better than monopolar transurethral resection of prostate. Urol Int 2004; 73: 258-61.
16. Seckiner I, Yesilli C, Akduman B, Altan K, Mungan NA. A prospective randomized study comparing bipolar plasmakinetic resection of the prostate with standard TURP. Urol Int 2006; 76: 139-43.

17. Patankar S, Jamkar A, Dobhada S, Gorde V. Plasmakinetic superpulse transurethral resection versus conventional transurethral resection of prostate. J Endourol 2006; 20: 215-19.

18. De Sio M, Autorino R, Quarto G, et al. Gyrus bipolar versus standard monopolar transurethral resection of the prostate: a randomized prospective trial. Urology 2006; 67: 69-72.

19. Erturhan S, Erbagci A, Seckiner I, Yagci F, Ustun A. Plasmakinetic resection of the prostate versus standard transurethral resection of the prostate: a prospective randomized trial with 1-year follow-up. Prostate Cancer Prostatic Dis 2007; 10: 97-100.

20. Bell CR, Murdock PJ, Pasi KJ, Morgan RJ. Thrombotic risk factors associated with transurethral prostatectomy. BJU Int 1999; 83: 984-9.

21. Melchior J, Valk WL, Foret JD, Mebust WK. Transurethral prostatectomy: computerized analysis of 2,223 consecutive cases. J Urol 1974; 112: 634-42.

22. Van Arsdalen KN, Barnes RW, Clarke G, Smith MJ, Koontz WW Jr. Deep vein thrombosis and prostatectomy. Urology 1983; 21: 461-3.

23. Parr NJ, Loh CS, Desmond AD. Transurethral resection of the prostate and bladder tumour without withdrawal of warfarin therapy. Br J Urol 1989; 64: 623-5.

24. Tscholl R, Straub W, Zingg E. Electroresection of the prostate in patients treated with heparin. J Urol 1980; 124: 221-2.

25. Cadroy Y, Harker LA, Hanson SR. Inhibition of plateletdependent thrombosis by low molecular weight heparin (CY222): comparison with standard heparin. J Lab Clin Med 1989; 114: 349-57.

26. van Den Belt AG, Prins MH, Lensing AW, et al. Fixed dose subcutaneous low molecular weight heparins versus adjusted dose unfractionated heparin for venous thromboembolism. Cochrane Database Syst Rev 2000; 2: CD001100.

27. Dunn AS, Turpie AG. Perioperative management of patients receiving oral anticoagulants: a systematic review. Arch Intern Med 2003; 163: 901-8.

28. Hoffman RM, MacDonald R, Wilt TJ. Laser prostatectomy for benign prostatic obstruction. Cochrane Database Syst Rev 2004; 1: CD001987.

29. Ruszat R, Wyler S, Forster T, et al. Safety and effectiveness of photoselective vaporization of the prostate (PVP) in patients on ongoing oral anticoagulation. Eur Urol 2007; 51: 1031-41.

30. Ekengren J, Hahn RG. Blood loss during transurethral resection of the prostate as measured by the HemoCue Photometer. Scand J Urol 1993; 27: 501-7. 